\title{
Progress towards Patient-Specific, Spatially- Continuous Radiobiological Dose Prescription and Planning in Prostate Cancer IMRT: An Overview
}

\author{
Emily Jungmin Her ${ }^{1, *(\mathbb{C})}$, Annette Haworth ${ }^{2}$, Pejman Rowshanfarzad ${ }^{1}$ and Martin A. Ebert ${ }^{1,3,4}$ \\ 1 Department of Physics, University of Western Australia, Crawley, WA 6009, Australia; \\ pejman.rowshanfarzad@uwa.edu.au (P.R.F.); Martin.Ebert@health.wa.gov.au (M.A.E.) \\ 2 Institute of Medical Physics, University of Sydney, Camperdown, NSW 2050, Australia; \\ annette.haworth@sydney.edu.au \\ 3 Department of Radiation Oncology, Sir Charles Gairdner Hospital, Nedlands, WA 6009, Australia \\ 4 5D Clinics, Claremont, WA 6010, Australia \\ * Correspondence: emily.her@research.uwa.edu.au; Tel.: +61-45-117-6532
}

Received: 9 January 2020; Accepted: 27 March 2020; Published: 1 April 2020

\begin{abstract}
Advances in imaging have enabled the identification of prostate cancer foci with an initial application to focal dose escalation, with subvolumes created with image intensity thresholds. Through quantitative imaging techniques, correlations between image parameters and tumour characteristics have been identified. Mathematical functions are typically used to relate image parameters to prescription dose to improve the clinical relevance of the resulting dose distribution. However, these relationships have remained speculative or invalidated. In contrast, the use of radiobiological models during treatment planning optimisation, termed biological optimisation, has the advantage of directly considering the biological effect of the resulting dose distribution. This has led to an increased interest in the accurate derivation of radiobiological parameters from quantitative imaging to inform the models. This article reviews the progress in treatment planning using image-informed tumour biology, from focal dose escalation to the current trend of individualised biological treatment planning using image-derived radiobiological parameters, with the focus on prostate intensity-modulated radiotherapy (IMRT).
\end{abstract}

Keywords: prostate cancer; precision medicine; biological optimisation

\section{Introduction}

It is well-established that prostate cancer (PCa) exhibits high multifocality and heterogeneity [1-3] and yet the current standard of care for PCa with external beam radiotherapy (EBRT) still largely remains a prescription of uniform, conformal dose distribution. Whole-gland therapy has traditionally been used due to the difficulty in precisely targeting tumour foci using conventional imaging techniques. With the advance in quantitative imaging, mainly magnetic resonance imaging (MRI) and positron emission tomography (PET), focal dose escalation to the dominant lesion has become popular.

"Dose painting" was first proposed by Ling et al. [4] to target tumour characteristics in addition to tumour location from quantitative imaging. Tumour subvolumes with a potential relative radiation resistance were identified and prescribed an escalation dose (a "boost dose"). This initial definition of dose painting is now labeled dose-painting-by-contours (DPbC) where the boost subvolume(s) within the target is created with image parameter threshold(s). The disadvantage with discrete volumes is that they are binary: Voxels inside a volume are assumed to represent a tumour or more aggressive disease. In reality, the tumour biology characteristics are continuous in a three-dimensional space. A more precise dose painting technique is called "dose-painting-by-numbers" (DPbN) [5]. The principle is to 
apply dose prescription at the voxel-level according to tumour characteristics such as clonogen density. Advanced imaging methods that can reveal biological information at the voxel level are now available, along with image-guided radiotherapy (IGRT), making DPbN feasible.

$\mathrm{DPbN}$ requires demonstration of correlation between imaging features and specific tumour biology characteristics [5-7] and a mathematical relationship to map an image-derived parameter to a voxel-level prescription dose. $\mathrm{DPbN}$ attempts to incorporate imaging data as a surrogate of biological information to improve clinical relevance. The top row of Figure 1 illustrates how quantitative imaging might be used to define an objective dose prescription for plan optimisation. However, conventional dose-based objectives rarely represent optimal tumour control. The ultimate goal of radiotherapy is to eradicate a tumour with minimal toxicity, which translates to a maximum tumour control probability (TCP) and minimum normal tissue complication probability (NTCP). Therefore, ideally, accurate radiobiological models of TCP and NTCP should be incorporated in both treatment planning and evaluation to produce dose distributions that are more likely to result in the desired treatment outcome (endpoint) rather than traditional dose-based planning objectives. A mechanistic TCP model requires the determination of voxel-level parameters, and the bottom row of Figure 1 illustrates how the same quantitative imaging might be used to obtain that information.

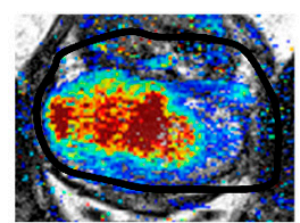

Quantitative imaging e.g. ADC, $\mathrm{K}^{\text {trans }}$

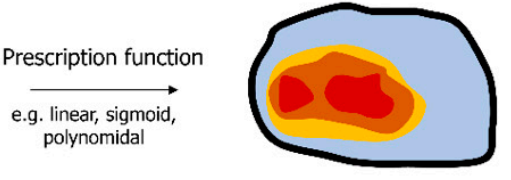

Prescribed dose distribution
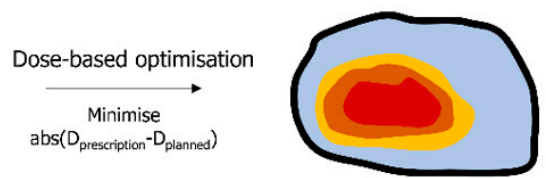

Planned dose distribution

$\underset{\text { Maximise TCP }}{\longrightarrow}$

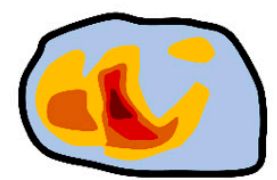

Planned dose distribution
Biological optimisation
Quantitative imaging e.g. ADC, $k^{\text {trans }}$
Translate intensity to $\stackrel{\longrightarrow}{\longrightarrow}$

e.g. mathematical functions, predictive models

Tumour biology distribution e.g. clonogen density, tumour grade

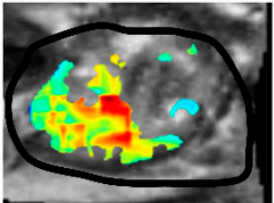

Figure 1. Pathways for optimising planned dose distribution based on the desired dose prescription (top) and based on the desired endpoint (bottom) using the same quantitative imaging data.

This article aims to review the progress in treatment planning using image-informed tumour biology, from focal dose escalation to the current trend of individualised biological treatment planning using voxel-level, image-derived radiobiological parameters to achieve optimal treatment outcomes, with the focus on prostate IMRT.

\section{Image-Guided Focal Dose Escalation in PCa IMRT}

Follow-up studies on treating PCa with a uniform-dose distribution have shown that local recurrences typically occur at the site of the primary tumour [8-11], suggesting the insufficiency of the conventional prescription dose. Dose escalation to the entire prostate gland is not practical as improved tumour control would be achieved at the expense of unacceptable normal tissue toxicity. Instead, delivering a focal boost dose to the dominant intraprostatic lesion (DIL) while irradiating the rest of the gland with the conventional prescription dose became popular. Concerns surrounding focal dose escalation include difficulty in accurately delineating DIL(s) [12]. Evolution of PCa quantitative imaging, multiparametric MRI (mpMRI) in particular, has been the driving force behind focal intraprostatic dose escalation. mpMRI is the use of multiple anatomical and quantitative MR sequences to image 
different tumour characteristics and has demonstrated improved sensitivity and specificity in cancer detection compared to using anatomical T2-weighted imaging (T2W) alone [13].

The FLAME trial investigated the treatment efficacy of focal dose escalation, the largest and the first randomised trial of its kind [14]. The FLAME trial used mpMRI to delineate DIL. Intermediateand high-risk PCa patients were randomised into the standard arm that delivered 77 Gy to the whole gland over 35 fractions or the experimental arm that received a focal boost to the DIL resulting in a total dose of 95 Gy. Focal dose escalation demonstrated comparable genitourinary (GU) and gastrointestinal (GI) toxicity to the standard arm up to two years post-treatment [15]. Murray et al. recently reported on preliminary results from the DELINEATE trial that applied focal dose escalation to conventionally-fractionated and hypofractionated IMRT for intermediate- and high-risk PCa [16]. An escalated dose of $82 \mathrm{~Gy}$ in 37 fractions (whole-gland dose $74 \mathrm{~Gy} / 37$ fractions) and $60 \mathrm{~Gy}$ to 20 fractions (whole-gland dose 67 Gy/20 fractions) was delivered to mpMRI-defined DIL. Similar normal tissue toxicity was observed in a one-year follow-up in comparison with studies without focal dose escalation. Results from other smaller studies involving focal dose escalation to mpMRI-defined DIL appear promising with good tumour control and favourable toxicity profiles [17,18].

\section{Deriving the Desired Dose Prescription from Voxel-Level Information}

A major limitation of escalating the dose in only the DIL delineated on imaging is the risk of missing other biologically significant tumours as PCa is a multifocal disease. Furthermore, a large inter-observer variation in DIL delineation on multimodality imaging has been observed [19-23]. While $\mathrm{DPbC}$ overcomes these shortcomings by systemically identifying subvolumes for homogeneous dose escalation, it fails to utilise the voxel-level tumour characteristic information provided by imaging in dose prescription. As $\mathrm{DPbN}$ has the potential to offer a more sophisticated method to deliver a spatially-varying dose distribution using the full range of image parameters, we will now focus on $\mathrm{DPbN}$ as the next step in incorporating image-informed tumour biology in treatment planning.

$\mathrm{DPbN}$ essentially establishes a mathematical link between imaging parameters and dose prescriptions that optimise chosen clinical endpoints [4,5]. The majority of DPbN studies assumed a linear relationship between image intensity and the required boost dose [24-28]. The linear function usually extends from a minimum dose, typically set to the current clinical dose prescription, and a maximum dose, set to a value that is considered "safe" for the target (Figure 2). The linear prescription function that is most widely adopted comes from the work of Vanderstraeten et al. [28]:

$$
\begin{array}{cc}
D_{i}=D_{\text {low }} & \text { if } I_{i} \leq I_{\text {low }} \\
D_{i}=D_{\text {low }}+\frac{I_{i}-I_{\text {low }}}{I_{\text {high }}-I_{\text {low }}}\left(D_{\text {high }}-D_{\text {low }}\right) & \text { if } I_{\text {low }}<I_{I}<I_{\text {high }} \\
D_{i}=D_{\text {high }} & \text { if } I_{i} \geq I_{\text {high }}
\end{array}
$$

where dose values increase linearly with voxel intensity $\left(I_{i}\right)$ between $D_{\text {low }}$ and $D_{\text {high }}$, respectively, corresponding to $I_{\text {low }}$ and $I_{\text {high }}$. In this work, $I_{\text {low }}$ was not chosen as the lowest intensity found in the image to minimise the effect of noise. Instead, the dose was escalated between $25 \%$ and $100 \%$ of the 95th percentile PET voxel intensity values.

Other commonly used prescription functions include sigmoidal (Figure 2) and polynomial functions. Sigmoidal functions capture the biological and clinical effects of local dose deposition. As there is no consensus on the optimal dose prescription, Bowen et al. investigated the sensitivity of IMRT planned dose conformity to variations in the mathematical function used [29]. The planning target volume (PTV) dose was set to 70 Gy plus a hypoxia surrogate uptake-dependent boost dose. Cu61-ATSM PET was used as the surrogate for cellular hypoxia. Two prescription functions were used for surrogate uptake dependence, in the form of either an $n$th order polynomial function or a sigmoidal function (Figure 3). Prescription functions based on polynomials were found to be the least constraining on their optimised plans, while prescriptions based on a sigmoid mapping function were 
the most demanding to deliver. Interestingly, integral doses to normal tissues were insensitive to the shape of the prescription function. This result demonstrates that as long as normal tissue constraints are met, treatment efficacy strongly depends on the ability to achieve the required dose dictated by tumour characteristic heterogeneities.

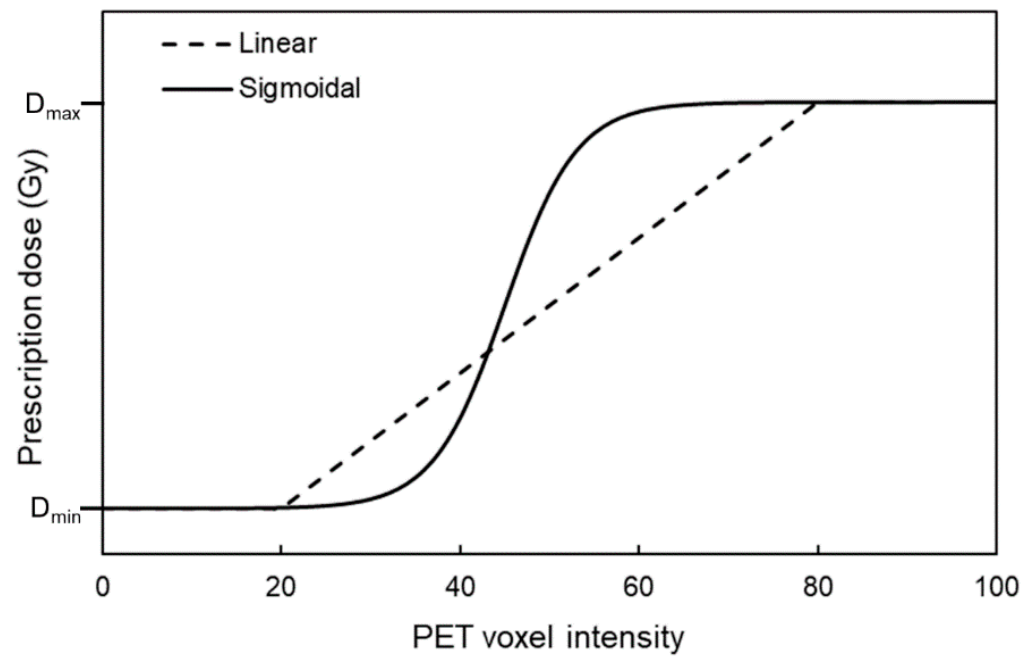

Figure 2. Linear and nonlinear (sigmoidal) prescription function relating the positron emission tomography (PET) voxel intensity to a local dose prescription for dose-painting-by-numbers (DPbN).
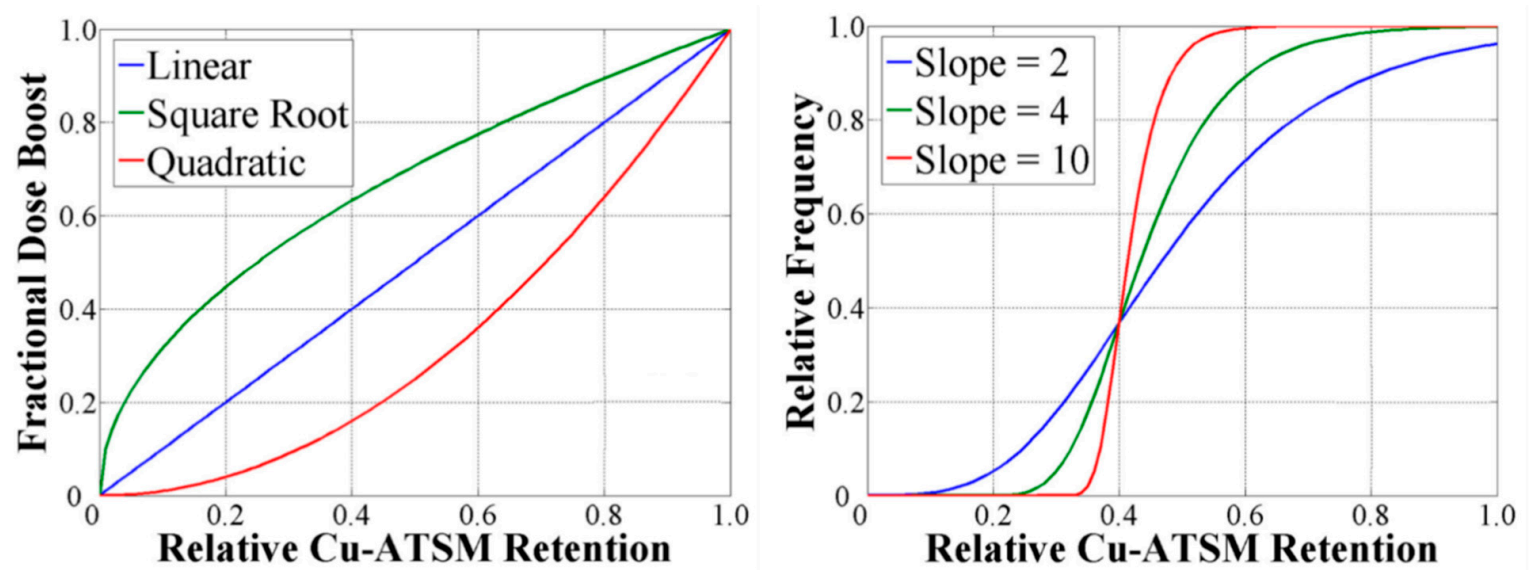

Figure 3. Quantitative forms for prescription functions. Left: Polynomial prescriptions, and right: Sigmoid prescriptions [29]. (C)Institute of Physics and Engineering in Medicine. Reproduced by permission of IOP Publishing. All rights reserved.

Instead of image intensities, quantitative parameters derived from imaging can also be used in the prescription function for improved biological relevance. One example is from the work of van Schie et al. [30] where a tumour probability (TP) map was used in a polynomial dose prescription function. The prescription dose was computed by:

$$
D_{\text {presc }, i}=D_{\min }+\left(D_{\max }-D_{\min }\right) \times T P_{i}^{n}
$$

where $D_{\text {presc, } i}$ is the prescription dose for voxel $i$. $D_{\min }$ and $D_{\max }$ are the minimum and maximum prescribed dose, respectively, and $n$ is the polynomial order of the mapping function. In their study, voxel-level TP maps were derived from 30 image features from mpMRI using a logistic regression model in combination with a priori tumour location information from radical prostatectomy patients.

A major drawback of $\mathrm{DPbN}$ studies is the use of arbitrarily-chosen functions that have not been validated against clinical outcomes data [24,25,29,31-34]. They are likely to be an oversimplification 
of the complex tumour dose-response. Furthermore, the maximum dose allowed in the focal dose escalation studies is chosen such that it has previously demonstrated safety $[14,35,36]$, but it does not necessarily ensure optimal tumour control. These, together with the limitation of dose-based treatment planning in producing patient-specific plans, make biological optimisation attractive.

\section{Deriving a Dose Distribution with the Desired Endpoint from Voxel-Level Information}

Biological optimisation could be broadly interpreted as any treatment planning method that incorporates biological information, but for this review, it is defined as an optimisation technique that uses a TCP model as the target objective. TCP was chosen as the focus as it directly represents the desired treatment outcome.

Early formulations of the modern linear-quadratic (LQ) model appeared in the late 1940s $[37,38]$ and became more established with extensive investigations in the 1970s and 1980s [39-49]. It has now become a preferred simplified mathematical description of cell survival in response to radiation. The model assumes that there are two components to the radiation damage; the linear component, $\alpha$, where the number of cell deaths is proportional to the dose; and the quadratic component, $\beta$, where the number of cell deaths is proportional to the square of the dose. $\alpha$ represents a single photon causing a lethal damage (intrinsic radiosensitivity of the tumour). $\beta$ represents two or more photons each causing a sublethal (potentially-repairable) damage, combining into a lethal form of damage (repair capability of the tumour). The survival fraction (SF) can be expressed as:

$$
S F=\exp \left(-\alpha D-\beta D^{2}\right)
$$

where $D$ is the total dose.

If it is assumed that any surviving clonogenic cell may repopulate a tumour, then the probability of tumour control is the same as the probability that all clonogenic cells are killed, given by:

$$
T C P=\exp \left(-N_{\text {initial }} \times S F\right)
$$

where $N_{\text {initial }}$ is the initial number of clonogenic cells and $S F$ is the surviving fraction after a course of treatment.

For fractionated EBRT with $n$ fractions and $d$ fractional dose in voxel $i$, the TCP of the corresponding voxel is formulated as:

$$
T C P_{i}=\exp \left(-\rho_{i} V_{i} \exp \left(-\alpha n d_{i}-\beta n d_{i}^{2}\right)\right)
$$

The initial number of clonogenic cells in voxel $i, N_{\text {initial }, i}$ can be expressed as the product of clonogen density per volume, $\rho_{i}$, and volume of the voxel, $V_{i}$.

Then, the overall TCP of a given dose distribution within the target structure is calculated as the product of all voxel TCPs:

$$
T C P=\prod_{i}^{N} T C P_{i}
$$

where $N$ is the total number of voxels in the target structure. The formulation requires an assumption that individual subregions of the tumour respond independently to the response of other subregions or nonlocal dose effects.

Taking account of the tumour growth dynamics where the combined influence of cell doubling, the proportion of proliferating cells, and accelerated clonogen proliferation are considered, the TCP can then be described by:

$$
T C P_{i}=\exp \left(-\rho_{i} V_{i} \exp \left(-\alpha n d_{i}-\beta n d_{i}^{2}+\ln (2) \frac{T_{\exp }-T_{k}}{T_{p o t}}\right)\right)
$$


Here, $T_{\exp }$ is the overall treatment time, $T_{k}$ is the kick-off time of the accelerated repopulation, and $T_{\text {pot }}$ is the potential doubling time. In applications to EBRT, temporal dependence on sublethal damage repair tends to be ignored but can be included for protracted treatments [50].

As radiosensitivity varies among individuals in a population, inter-patient radiosensitivity can be taken into account by applying a population distribution to the radiosensitivity parameter $\alpha$ and then utilising a normalisation with a weighted sum:

$$
T C P_{i}=\frac{\sum_{k} w\left(\alpha_{k}\right) T C P_{i}\left(\alpha_{k}\right)}{\sum_{k} w\left(\alpha_{k}\right)}
$$

where $w\left(\alpha_{k}\right)$ is the population distribution function of $\alpha$. A common quantitative form is that of a normal distribution, described by a mean $\bar{\alpha}$ and standard deviation $\sigma_{\alpha}$.

Hypoxic tumour cells are radioresistant and hence the presence of hypoxia alters the radiosensitivity parameters. The amount which the tumour radiosensitivity changes is described by the oxygen enhancement ratio (OER):

$$
\begin{aligned}
\alpha_{\text {hypoxic }} & =\frac{\alpha}{O E R} \\
\beta_{\text {hypoxic }} & =\frac{\beta}{O E R^{2}}
\end{aligned}
$$

\section{Biological Optimisation of Prostate IMRT Using Population-Based Parameters}

Early attempts in incorporating TCP in biological optimisation often involved maximisation of subvolume TCP with limited modeling of intra-tumour heterogeneity from quantitative imaging. Kim and Tomé [51] used a phenomenological TCP model that only has two radiobiological parameters, the dose which yields a TCP of $50 \%, D_{50}$, and the slope of the TCP curve at $D_{50}, \gamma_{50}$ :

$$
\operatorname{TCP}(D)=\frac{1}{1+\left(\frac{D_{50}}{D}\right)^{4 / 50}}
$$

Each subvolume was assigned different values of the radiobiological parameters depending on the risk of recurrence. All voxels within a subvolume were assumed to possess identical tumour characteristics. $D_{50}$ values were derived from the published clinical data of Levegrün et al. [52]. A variety of subvolume (nodule) geometries was created arbitrarily to test the feasibility of biological optimisation (Figure 4). The biological optimisation aimed to maximise TCP while simultaneously minimising NTCP [53]. For all subvolume geometries investigated, the biological optimisation was feasible without a significant increase in NTCP compared to conventional uniform-dose plans.

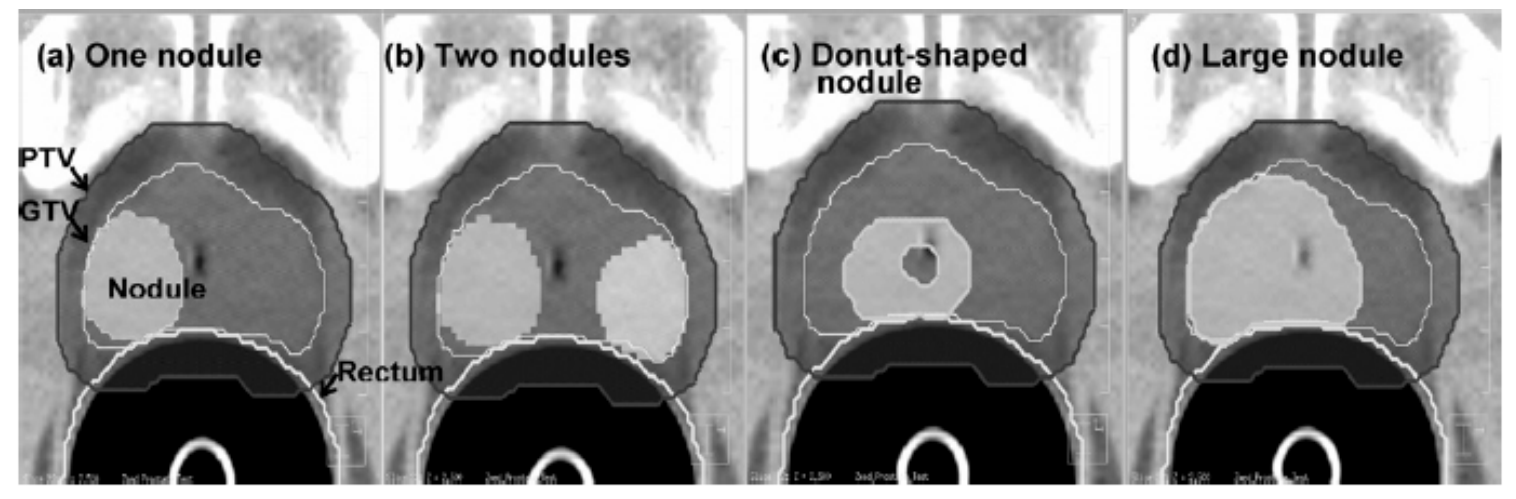

Figure 4. Subvolume (nodule) geometries. (a) One-nodule case, (b) two-nodule-case, (c) donut-shapednodule case, (d) big-nodule case. Reproduced with permission from [51]. 
Uzan et al. [54] maximised the TCP of the DIL, identified on quantitative MRI, while satisfying the NTCP limits for grade 2-3 rectal bleeding and grade 3 faecal incontinence. For TCP modeling, it was assumed that all clonogens are located uniformly inside the DIL with a constant clonogen density and any clonogens outside the DIL can be controlled by the dose to the clinical target volume (CTV). The radiosensitivity parameter, $\alpha$, was assumed to be normally distributed within a population described by $\bar{\alpha}=0.185 \mathrm{~Gy}^{-1}$ and $\sigma_{\alpha}=0.053 \mathrm{~Gy}^{-1}$, introducing inter-tumour heterogeneity. Biological optimisation was performed using research software and the resulting plan was replanned on clinical software using the dose-volume (DV) metrics. Uzan et al. reported the potential of biological optimisation in yielding high tumour control with promising toxicity profile. Only two patients experienced grade 2 urinary toxicity and two patients had $\leq$ grade 2 late rectal toxicity over a median follow-up of 36 months.

More sophisticated intra-tumour biology was modeled for Betts et al. and Haworth et al. [55-57], where they used location-dependent cell density distributions to drive biological optimisation of prostate low-dose-rate brachytherapy. The prostate was divided into the apex, mid, and base segments where each was further divided into four quadrants. The probability of finding a tumour in each quadrant [58] was used to assign an initial clonogen number to the corresponding quadrant. Biological optimisation determined the seed placement so that the overall TCP was maximised while maintaining the organs at risk (OAR) DV constraints and restrictions on seed arrangement. The biologically-optimised plans were able to reduce the dose to the urethra while maintaining a high TCP. This study also demonstrated robustness to random seed displacement compared to conventional plans.

\section{Biological Optimisation of Prostate IMRT Using Patient-Specific, Voxel-Level Parameters}

While population-based parameters can be extracted from large trial datasets, spatial voxel-level tumour characteristics are ideal for a patient-specific $\mathrm{DPbN}$ plan. Deriving an accurate, quantitative relationship between image features and radiobiological parameters is challenging, leading to very few treatment planning studies incorporating image-derived PCa parameters so far.

Dircherl et al. [59] used prostate 18F-Choline PET images to derive a voxel-level proliferation rate and cell density which were then used to compute dose distributions with maximum TCP. An independent linear relationship between each parameter and standard uptake value from PET was assumed. A voxel-wise prescription function was derived such that it ensures a maximum TCP is given for a fixed target integral dose. While a voxel-level TCP was included in treatment planning, the derived plans were not truly "biologically-optimised" since the optimiser did not iteratively evaluate TCP to derive the optimal deliverable dose distribution that maximises TCP. Instead, an objective function that minimised the difference between the prescribed dose and the planned dose was used. While this approach is likely to produce a high TCP, the mathematical formulation of TCP dictates that maximal TCP is achieved when individual voxel TCPs are very high and identical to each other [60]. Therefore, the presence of one single voxel with a low TCP will limit the overall TCP. Failure to incorporate TCP evaluation within the optimiser could result in suboptimal treatment plans.

Grönlund et al. [61] used a phenomenological TCP model in biological optimisation of prostate radiotherapy. Apparent diffusion coefficient (ADC) calculated from diffusion-weighted MR has been correlated with Gleason score as increased cellularity restricts diffusion $[62,63]$. Using published correlations, Gleason score of the voxel of interest, $G_{i}$, was determined from ADC map. Then, voxel TCP was computed as:

$$
T C P_{i}=\frac{1}{1+\left(\frac{D_{50}\left(G_{i}\right)}{D}\right)^{4 \gamma_{50}\left(G_{i}\right)}}
$$

where dose-response parameters $D_{50}$ and $\gamma_{50}$ are functions of the assigned Gleason score. Gleason score and dose-response were related by using preradiotherapy biopsy and postradiotherapy outcomes data from 122 patients treated with a uniform dose distribution. The parameters were derived such that they agreed with the observed freedom from biochemical failure rate at five years postradiotherapy. 
The proposed formalism demonstrated a potential for increasing TCP without extra dose burden. However, it was a dose redistribution study without the consideration of normal tissue toxicity.

While improved radiobiological models have been used in biological optimisation, the derivation of the model parameters from imaging has largely been limited to invalidated functions of image intensity. The combination of radiomics and machine learning methods appears to be a potential solution for accurate image-derived radiobiological parameters. Radiomics aims to extract quantitative features from images. These features can then be used to develop predictive models using machine learning methods when "ground-truth" voxel-level data is available. Many investigators have explored and yielded promising results from using radiomics and machine learning of mpMRI for PCa detection [64-68], tumour aggressiveness (Gleason score) classification, and staging [62,69-74]. Voxel-level tumour biology distributions generated by predictive models using mpMRI can then be used to drive biological optimisation of prostate radiotherapy as demonstrated by the bottom row of Figure 1.

One such approach proposed by Haworth et al. is called the biofocused radiotherapy (BiRT) $[57,75]$. The BiRT approach utilises machine learning methods to generate voxel maps of tumour biology information from imaging data, which is then used in the calculation of a parameterised voxel-level TCP objective for plan optimisation. Using "ground-truth" histology information from a database of prostatectomy patients and presurgical mpMRI spatially registered with histology sections, reliable predictive models can be made without the explicit understanding of underlying biological and physical processes (Figure 5). Imaging biomarkers for predicting prostate tumour location, cell density, and tumour grade from mpMRI have been developed [65,71,76]. Image registration methods have recently been refined further to allow voxel-wise correlation of PET/CT with mpMRI and histology data of the prostate [77]. Work is currently underway to use the voxel-level, patient-specific tumour information from mpMRI and imaging biomarkers to drive biological optimization of prostate IMRT. Preliminary investigation has demonstrated a reduction in dose to the rectum and bladder for biofocused prostate IMRT compared to conventional dose- and DV-based methods [78,79].

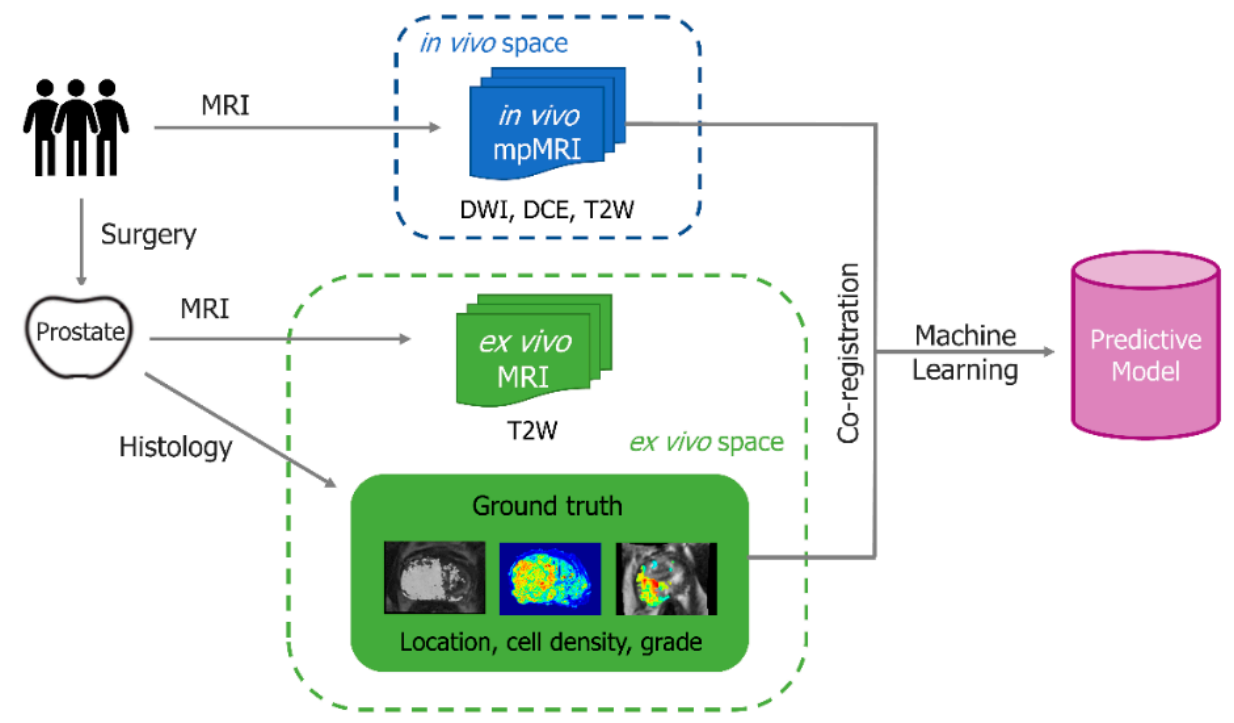

Figure 5. A diagram showing the predictive model development process for biofocused radiotherapy (BiRT). Prior to radical prostatectomy, in vivo multiparametric magnetic resonance imaging (mpMRI) data is collected. mpMRI feature extraction and selection is performed. Ground truth tumour biology maps are derived from removed prostate histology. Ground truth maps and mpMRI data are spatially registered using ex vivo and in vivo T2W images and machine learning methods are used to build predictive models. Regarding Figure 1, the resulting predictive models can be utilised to derive the tumour biology distribution from an individual patient's multi-parametric images. 


\section{Ongoing and Future Considerations}

The future of prostate radiotherapy treatment planning is promising with work underway to improve various aspects of biological optimisation. However, it is still far from clinical deployment, largely owing to uncertainties in radiobiological models and their parameters. In addition to methods of incorporating these uncertainties in treatment planning optimisation, hypofractionation and adaptive therapy are of interest in PCa radiotherapy. It is expected that future research addressing these issues, some of which are outlined below, will lead to the realisation of patient-specific, biologically-optimised radiotherapy as the standard of care.

\subsection{More Complete TCP Models}

There are several significant limitations in current TCP models that need to be overcome. Firstly, these models are usually mechanistic in nature and lack the ability to incorporate important nondosimetric clinical factors such as age, interactions with other treatment responses. Secondly, the TCP model described above fundamentally assumes that clonogens do not communicate with each other, that cell killing events are independent and that clonogens only respond to local dose deposition. These assumptions ignore the bystander effect where cytotoxic effects are seen in nonirradiated cells. The indirect effects of ionising radiation in tumour control is another aspect of tumour biology that has not been incorporated in TCP modeling. One such effect is the vascular effect where high local doses create an unfavourable tumour microenvironment through vascular damage. In studies with experimental tumours, a dose/fraction size greater than $10 \mathrm{~Gy}$ has demonstrated the ability to induce severe vascular damage such as endothelial apoptosis that leads to tumour cell killing through the reduced blood supply, thus starving the tumour of oxygen and other nutrients [80-83]. It has also been suggested that high dose/fraction irradiation triggers an immune response and thereby eradicates tumour cells that escaped radiation-induced death [84]. The radiation-induced immune response is also thought to be related to the regression of lesions outside the radiation field, called the abscopal effect [85]. The above mechanisms, together with patient-specific genomic factors, can be integrated into a mechanistic radiobiological model as presented above. Such a model would, however, have a very large number of patient-specific, spatially and temporally-varying parameters. A considerable effort will be required to develop imaging or other techniques to derive such parameters. Sensitivity analyses can identify which parameters need to be derived with the highest priority [86].

\subsection{Sensitivity and Specificity of Quantitative Imaging}

The reporting of sensitivity and specificity of quantitative imaging in detecting tumour biology information is necessary for a complete understanding of the accuracy of a biological optimization approach in treatment planning. Prostate mpMRI has primarily been investigated in tumour detection and localisation demonstrating high sensitivity and specificity $[87,88]$. There is limited literature on other tumour characteristics such as cellular hypoxia as they largely remain in the investigational stage [89]. The effect of quantitative imaging uncertainties on treatment planning has also been investigated in a limited number of studies. For example, Kim and Tomé investigated the effect of imaging accuracy on biologically-optimised prostate IMRT plans [90]. Loss of sensitivity was modeled as misclassification of "high-risk" tumour voxels as "low-risk"; and loss in specificity as misclassification of "low-risk" tumour voxels as "high-risk". Their results suggest that TCP of a biologically-optimised plan is more sensitive to a loss in quantitative imaging sensitivity compared to the loss in specificity. This is expected since a "low-risk" voxel classified as "high-risk" will still be treated with a sufficient dose whereas the optimiser cannot adequately account for a "high-risk" voxel misclassified as "low-risk".

For biological optimisation where a radiobiological model is informed by imaging via predictive models, quantitative imaging accuracy is combined with other model uncertainties as overall predictive model accuracy. Factors that influence model accuracy include reconstruction methods, machine 
learning methods, and size of the training dataset. The effect of the overall uncertainty in the predicted parameter value on the resultant plan should be performed on a case-by-case basis.

\subsection{Robustness to Uncertainties}

The standard approach to incorporate treatment delivery uncertainty in radiotherapy has been the use of a margin surrounding the CTV to generate a PTV [91]. It is assumed that the CTV only moves within the boundaries of the PTV and therefore ensures that the prescribed uniform dose is delivered to the CTV with a specific likelihood. However, the PTV concept has several limitations as discussed by Unkelbach et al. [92], which includes the inability to guarantee the optimal balance between tumour control and normal tissue sparing. Robust optimisation or probabilistic treatment planning methods have been developed to overcome PTV limitations by directly incorporating uncertainties in treatment planning optimisation [93-100]. Probabilistic treatment planning methods are particularly important for biological optimisation since the use of margins for nonuniform dose distributions within the CTV is problematic. Furthermore, it is relatively easier to incorporate uncertainties from the additional steps that involve imaging data, image registration, and radiobiological modeling. Clinical implementation of biological optimisation, therefore, requires knowledge of the sources and effects of geometric uncertainties on the dose distribution. An underestimation of geometric errors, the systematic component, in particular, may result in treatment failure.

\subsection{Hypofractionation}

With a consensus that the $\alpha / \beta$ ratio of PCa is less than 5 Gy [101-103] and the neighbouring rectum and bladder have a higher $\alpha / \beta$ ratio of 5-8 Gy [104,105], hypofractionation can be expected to improve treatment outcome. Many randomised clinical trials investigating treatment safety and efficacy of hypofractionated treatment compared to standard fractionation have been completed with encouraging results [106-113]. However, an increase in acute GI and late GU has been reported for hypofractionation studies [114,115] due to difficulty in maintaining OAR doses at acceptable levels while delivering a high uniform dose to the PTV. Biological optimisation has the potential to allow a reduction in dose to the OARs through more efficient distribution of dose to the PTV. Biological optimisation with population-based TCP and NTCP objective functions in the hypofractionated treatment of high-risk PCa has previously demonstrated good biochemical control with comparable urinary and bowel toxicity to conventional fractionation [116]. As such, the radiobiological advantage of hypofractionation may be better realised with patient-specific TCP models.

\subsection{Adaptive Therapy}

Standard radiotherapy assumes that the tumour response will be consistent throughout treatment. However, cancer is known to adapt to therapies and its biological characteristics are often temporally and spatially heterogeneous. To address the time-dependent changes in tumour characteristics, an adaptive therapeutic strategy has been proposed [117]. Adaptive therapy evaluates treatment response by comparing imaging data acquired before treatment commences (baseline) and at various time points during treatment to adapt the initial dose distribution accordingly. Hypoxia is one of the tumour characteristics often targeted for adaptive therapy due to its highly spatially- and temporally-variable nature and has primarily been investigated in head and neck cancer using PET with promising results [33,118-121]. There are, however, challenges to overcome before the clinical application of adaptive therapy can be realised. Adaptive therapy is labour-intensive, especially for biological optimisation since quantitative image acquisition and registration, analysis, and treatment planning must be completed for each stage of the therapy. While this may be impractical for conventional fractionation schedules, it is potentially feasible for PCa since the low $\alpha / \beta$ ratio allows extreme hypofractionation with less than five fractions. The optimal imaging frequency and timing remains unknown. 


\section{Conclusions}

Advances in quantitative imaging of PCa allow better targeting of the tumour using radiobiological information derived from the images. Clinical studies that focused on translating image parameters to the desired dose demonstrated promising results in improving tumour control with minimal normal tissue toxicity. However, the direct consideration of the desired endpoint during treatment planning optimisation appears to be the most logical approach for clinical implementation of personalised medicine in prostate radiotherapy. It is expected that the accumulation of PCa radiobiology information and their associated uncertainties will lead to the realisation of patient-specific, biologically-optimised radiotherapy as the standard of care.

Funding: This work was supported by Project Grant 1126955 from the Australian National Health and Medical Research Council.

Conflicts of Interest: The authors declare no conflict of interest.

\section{References}

1. Meiers, I.; Waters, D.J.; Bostwick, D.G. Preoperative prediction of multifocal prostate cancer and application of focal therapy: Review 2007. Urology 2007, 70, 3-8. [CrossRef] [PubMed]

2. Løvf, M.; Zhao, S.; Axcrona, U.; Johannessen, B.; Bakken, A.C.; Carm, K.T.; Hoff, A.M.; Myklebost, O.; Meza-Zepeda, L.A.; Lie, A.K.; et al. Multifocal Primary Prostate Cancer Exhibits High Degree of Genomic Heterogeneity. Eur. Urol. 2019, 75, 498-505. [CrossRef] [PubMed]

3. Wei, L.; Wang, J.; Lampert, E.; Schlanger, S.; DePriest, A.D.; Hu, Q.; Gomez, E.C.; Murakam, M.; Glenn, S.T.; Conroy, J.; et al. Intratumoral and Intertumoral Genomic Heterogeneity of Multifocal Localized Prostate Cancer Impacts Molecular Classifications and Genomic Prognosticators. Eur. Urol. 2017, 71, 183-192. [CrossRef] [PubMed]

4. Ling, C.C.; Humm, J.; Larson, S.; Amols, H.; Fuks, Z.; Leibel, S.; Koutcher, J.A. Towards multidimensional radiotherapy (MD-CRT): Biological imaging and biological conformality. Int. J. Radiat. Oncol. Biol. Phys. 2000, 47, 551-560. [CrossRef]

5. Bentzen, S.M. Theragnostic imaging for radiation oncology: Dose-painting by numbers. Lancet Oncol. 2005, 6, 112-117. [CrossRef]

6. Bentzen, S.M.; Gregoire, V. Molecular Imaging-Based Dose Painting: A Novel Paradigm for Radiation Therapy Prescription. Semin. Radiat. Oncol. 2011, 21, 101-110. [CrossRef] [PubMed]

7. Thorwarth, D. Functional imaging for radiotherapy treatment planning: Current status and future directions-A review. Br. J. Radiol. 2015, 88. [CrossRef] [PubMed]

8. Chopra, S.; Toi, A.; Taback, N.; Evans, A.; Haider, M.A.; Milosevic, M.; Bristow, R.G.; Chung, P.; Bayley, A.; Morton, G.; et al. Pathological predictors for site of local recurrence after radiotherapy for prostate cancer. Int. J. Radiat. Oncol. Biol. Phys. 2012, 82, e441-e448. [CrossRef] [PubMed]

9. Arrayeh, E.; Westphalen, A.C.; Kurhanewicz, J.; Roach, M.; Jung, A.J.; Carroll, P.R.; Coakley, F.V. Does local recurrence of prostate cancer after radiation therapy occur at the site of primary tumor? Results of a longitudinal MRI and MRSI study. Int. J. Radiat. Oncol. Biol. Phys. 2012, 82, e787-e793. [CrossRef] [PubMed]

10. Pucar, D.; Hricak, H.; Shukla-Dave, A.; Kuroiwa, K.; Drobnjak, M.; Eastham, J.; Scardino, P.T.; Zelefsky, M.J. Clinically significant prostate cancer local recurrence after radiation therapy occurs at the site of primary tumor: Magnetic resonance imaging and step-section pathology evidence. Int. J. Radiat. Oncol. Biol. Phys. 2007, 69, 62-69. [CrossRef] [PubMed]

11. Cellini, N.; Morganti, A.G.; Mattiucci, G.C.; Valentini, V.; Leone, M.; Luzi, S.; Manfredi, R.; Dinapoli, N.; Digesu', C.; Smaniotto, D. Analysis of intraprostatic failures in patients treated with hormonal therapy and radiotherapy: Implications for conformal therapy planning. Int. J. Radiat. Oncol. Biol. Phys. 2002, 53, 595-599. [CrossRef]

12. Mouraviev, V.; Villers, A.; Bostwick, D.G.; Wheeler, T.M.; Montironi, R.; Polascik, T.J. Understanding the pathological features of focality, grade and tumour volume of early-stage prostate cancer as a foundation for parenchyma-sparing prostate cancer therapies: Active surveillance and focal targeted therapy. BJU Int. 2011, 108, 1074-1085. [CrossRef] [PubMed] 
13. Turkbey, B.; Mani, H.; Shah, V.; Rastinehad, A.R.; Bernardo, M.; Pohida, T.; Pang, Y.; Daar, D.; Benjamin, C.; McKinney, Y.L.; et al. Multiparametric 3T prostate magnetic resonance imaging to detect cancer: Histopathological correlation using prostatectomy specimens processed in customized magnetic resonance imaging based molds. J. Urol. 2011, 186, 1818-1824. [CrossRef]

14. Lips, I.M.; van der Heide, U.A.; Haustermans, K.; van Lin, E.N.; Pos, F.; Franken, S.P.; Kotte, A.N.; van Gils, C.H.; van Vulpen, M. Single blind randomized Phase III trial to investigate the benefit of a focal lesion ablative microboost in prostate cancer (FLAME-trial): Study protocol for a randomized controlled trial. Trials 2011, 12, 255. [CrossRef]

15. Monninkhof, E.M.; van Loon, J.W.L.; van Vulpen, M.; Kerkmeijer, L.G.W.; Pos, F.J.; Haustermans, K.; van den Bergh, L.; Isebaert, S.; McColl, G.M.; Smeenk, R.J.; et al. Standard whole prostate gland radiotherapy with and without lesion boost in prostate cancer: Toxicity in the FLAME randomized controlled trial. Radiother. Oncol. 2018, 127, 74-80. [CrossRef]

16. Murray, J.R.; Tree, A.C.; Alexander, E.J.; Sohaib, A.; Hazell, S.; Thomas, K.; Gunapala, R.; Parker, C.C.; Huddart, R.A.; Gao, A.; et al. Standard and Hypofractionated Dose Escalation to Intraprostatic Tumor Nodules in Localized Prostate Cancer: Efficacy and Toxicity in the DELINEATE Trial. Int. J. Radiat. Oncol. Biol. Phys. 2020, 106, 715-724. [CrossRef]

17. Blumenfeld, P.; Chowdhary, M.; Deane, L.A.; Pfanzelter, N.; Shors, S.; Braun, R.; White, G.M.; Coogan, C.; Hoeksema, J.; Khare, N.; et al. Multi-parametric MRI guided dose escalated radiotherapy for treatment of localized prostate cancer (PCa): Initial toxicity results of a prospective phase II trial. JCO 2018, 36, 25. [CrossRef]

18. Meshman, J.; Farnia, B.; Stoyanova, R.; Reis, I.; Abramowitz, M.; Dal Pra, A.; Horwitz, E.M.; Pollack, A. Biopsy positivity in prostate cancer patients undergoing mpMRI-targeted radiation dose escalation. JCO 2020, 38, 336. [CrossRef]

19. van Schie, M.A.; Dinh, C.V.; van Houdt, P.J.; Pos, F.J.; Heijmink, S.W.T.J.P.; Kerkmeijer, L.G.W.; Kotte, A.N.T.J.; Oyen, R.; Haustermans, K.; van der Heide, U.A. Contouring of prostate tumors on multiparametric MRI: Evaluation of clinical delineations in a multicenter radiotherapy trial. Radiother. Oncol. 2018, 128, 321-326. [CrossRef]

20. Steenbergen, P.; Haustermans, K.; Lerut, E.; Oyen, R.; De Wever, L.; Van den Bergh, L.; Kerkmeijer, L.G.W.; Pameijer, F.A.; Veldhuis, W.B.; van der Voort van Zyp, J.R.N.; et al. Prostate tumor delineation using multiparametric magnetic resonance imaging: Inter-observer variability and pathology validation. Radiother. Oncol. 2015, 115, 186-190. [CrossRef]

21. Anwar, M.; Westphalen, A.C.; Jung, A.J.; Noworolski, S.M.; Simko, J.P.; Kurhanewicz, J.; Roach, M.; Carroll, P.R.; Coakley, F.V. Role of endorectal MR imaging and MR spectroscopic imaging in defining treatable intraprostatic tumor foci in prostate cancer: Quantitative analysis of imaging contour compared to whole-mount histopathology. Radiother. Oncol. 2014, 110, 303-308. [CrossRef] [PubMed]

22. Bratan, F.; Niaf, E.; Melodelima, C.; Chesnais, A.L.; Souchon, R.; Mège-Lechevallier, F.; Colombel, M.; Rouvière, $\mathrm{O}$. Influence of imaging and histological factors on prostate cancer detection and localisation on multiparametric MRI: A prospective study. Eur. Radiol. 2013, 23, 2019-2029. [CrossRef]

23. Rischke, H.C.; Nestle, U.; Fechter, T.; Doll, C.; Volegova-Neher, N.; Henne, K.; Scholber, J.; Knippen, S.; Kirste, S.; Grosu, A.L.; et al. 3 Tesla multiparametric MRI for GTV-definition of Dominant Intraprostatic Lesions in patients with Prostate Cancer-an interobserver variability study. Radiat. Oncol. 2013, 8, 183. [CrossRef] [PubMed]

24. Alber, M.; Paulsen, F.; Eschmann, S.M.; Machulla, H.J. On biologically conformal boost dose optimization. Phys. Med. Biol. 2003, 48, N31-N35. [CrossRef] [PubMed]

25. Arnesen, M.R.; Knudtsen, I.S.; Rekstad, B.L.; Eilertsen, K.; Dale, E.; Bruheim, K.; Helland, Å.; Løndalen, A.M.; Hellebust, T.P.; Malinen, E. Dose painting by numbers in a standard treatment planning system using inverted dose prescription maps. Acta Oncol. 2015, 54, 1607-1613. [CrossRef]

26. Berwouts, D.; Olteanu, L.A.M.; Speleers, B.; Duprez, F.; Madani, I.; Vercauteren, T.; De Neve, W.; De Gersem, W. Intensity modulated arc therapy implementation in a three phase adaptive 18F-FDG-PET voxel intensity-based planning strategy for head-and-neck cancer. Radiat. Oncol. 2016, 11, 52. [CrossRef] [PubMed] 
27. Das, S.K.; Miften, M.M.; Zhou, S.; Bell, M.; Munley, M.T.; Whiddon, C.S.; Craciunescu, O.; Baydush, A.H.; Wong, T.; Rosenman, J.G.; et al. Feasibility of optimizing the dose distribution in lung tumors using fluorine-18-fluorodeoxyglucose positron emission tomography and single photon emission computed tomography guided dose prescriptions. Med. Phys. 2004, 31, 1452-1461. [CrossRef]

28. Vanderstraeten, B.; Duthoy, W.; Gersem, W.D.; Neve, W.D.; Thierens, H. [18F]fluoro-deoxy-glucose positron emission tomography ([18F]FDG-PET) voxel intensity-based intensity-modulated radiation therapy (IMRT) for head and neck cancer. Radiother. Oncol. 2006, 79, 249-258. [CrossRef]

29. Bowen, S.R.; Flynn, R.T.; Bentzen, S.M.; Jeraj, R. On the sensitivity of IMRT dose optimization to the mathematical form of a biological imaging-based prescription function. Phys. Med. Biol. 2009, 54, 1483-1501. [CrossRef]

30. van Schie, M.A.; Steenbergen, P.; Dinh, C.V.; Ghobadi, G.; van Houdt, P.J.; Pos, F.J.; Heijmink, S.W.T.J.P.; van der Poel, H.G.; Renisch, S.; Vik, T.; et al. Repeatability of dose painting by numbers treatment planning in prostate cancer radiotherapy based on multiparametric magnetic resonance imaging. Phys. Med. Biol. 2017, 62, 5575-5588. [CrossRef]

31. Thorwarth, D.; Eschmann, S.-M.; Paulsen, F.; Alber, M. Hypoxia Dose Painting by Numbers: A Planning Study. Int. J. Radiat. Oncol. Biol. Phys. 2007, 68, 291-300. [CrossRef] [PubMed]

32. Vanderstraeten, B.; Gersem, W.D.; Duthoy, W.; Neve, W.D.; Thierens, H. Implementation of biologically conformal radiation therapy (BCRT) in an algorithmic segmentation-based inverse planning approach. Phys. Med. Biol. 2006, 51, N277-N286. [CrossRef] [PubMed]

33. Yan, D.; Chen, S.; Krauss, D.J.; Chen, P.Y.; Chinnaiyan, P.; Wilson, G.D. Tumor Voxel Dose-Response Matrix and Dose Prescription Function Derived Using 18F-FDG PET/CT Images for Adaptive Dose Painting by Number. Int. J. Radiat. Oncol. Biol. Phys. 2019, 104, 207-218. [CrossRef] [PubMed]

34. Zamboglou, C.; Sachpazidis, I.; Koubar, K.; Drendel, V.; Wiehle, R.; Kirste, S.; Mix, M.; Schiller, F.; Mavroidis, P.; Meyer, P.T.; et al. Evaluation of intensity modulated radiation therapy dose painting for localized prostate cancer using 68 Ga-HBED-CC PSMA-PET/CT: A planning study based on histopathology reference. Radiother. Oncol. 2017, 123, 472-477. [CrossRef]

35. Zamboglou, C.; Thomann, B.; Koubar, K.; Bronsert, P.; Krauss, T.; Rischke, H.C.; Sachpazidis, I.; Drendel, V.; Salman, N.; Reichel, K.; et al. Focal dose escalation for prostate cancer using 68Ga-HBED-CC PSMA PET/CT and MRI: A planning study based on histology reference. Radiat. Oncol. 2018, 13, 81. [CrossRef]

36. Wong, W.W.; Schild, S.E.; Vora, S.A.; Ezzell, G.A.; Nguyen, B.D.; Ram, P.C.; Roarke, M.C. Image-guided radiotherapy for prostate cancer: A prospective trial of concomitant boost using indium-111-capromab pendetide (ProstaScint) imaging. Int. J. Radiat. Oncol. Biol. Phys. 2011, 81, e423-e429. [CrossRef]

37. Lea, D.E. Actions of Radiations on Living Cells; Cambridge University Press: London, UK, 1946.

38. Lea, D.E.; Catcheside, D.G. The mechanism of the induction by radiation of chromosome aberrations inTradescantia. J. Genetics 1942, 44, 216-245. [CrossRef]

39. Barendsen, G.W. Dose fractionation, dose rate and iso-effect relationships for normal tissue responses. Int. J. Radiat. Oncol. Biol. Phys. 1982, 8, 1981-1997. [CrossRef]

40. Curtis, S.B. Lethal and potentially lethal lesions induced by radiation-A unified repair model. Radiat. Res. 1986, 106, 252-270. [CrossRef]

41. Dale, R.G. The application of the linear-quadratic dose-effect equation to fractionated and protracted radiotherapy. Br. J. Radiol. 1985, 58, 515-528. [CrossRef]

42. Douglas, B.G.; Fowler, J.F. Letter: Fractionation schedules and a quadratic dose-effect relationship. Br. J. Radiol. 1975, 48, 502-504. [CrossRef] [PubMed]

43. Fowler, J.F. The linear-quadratic formula and progress in fractionated radiotherapy. BJR 1989, 62, 679-694. [CrossRef] [PubMed]

44. Schultheiss, T.E.; Zagars, G.K.; Peters, L.J. An explanatory hypothesis for early- and late-effect parameter values in the LQ model. Radiother. Oncol. 1987, 9, 241-248. [CrossRef]

45. Thames, H.D. An "incomplete-repair" model for survival after fractionated and continuous irradiations. Int. J. Radiat. Biol. Relat. Stud. Phys. Chem. Med. 1985, 47, 319-339. [CrossRef] [PubMed]

46. Thames, H.D.; Ang, K.K.; Stewart, F.A.; van der Schueren, E. Does incomplete repair explain the apparent failure of the basic LQ model to predict spinal cord and kidney responses to low doses per fraction? Int. J. Radiat. Biol. 1988, 54, 13-19. [CrossRef] 
47. Sinclair, W.K. The shape of radiation survival curves of mammalian cells cultured in vitro. In Biophysical Aspects of Radiation Quality; Techn Rep Series 58 IAEA; International Atomic Energy Agency (IAEA): Vienna, Austria, 1966; pp. 21-43.

48. Chadwick, K.H.; Leenhouts, H.P. A molecular theory of cell survival. Phys. Med. Biol. 1973, 18, 78-87. [CrossRef]

49. Kellerer, A.M.; Rossi, H.H. A Generalized Formulation of Dual Radiation Action. Radiat. Res. 1978, 75 , 471-488. [CrossRef]

50. Dasu, A.; Toma-Dasu, I. Will intrafraction repair have negative consequences on extreme hypofractionation in prostate radiation therapy? Br. J. Radiol. 2015, 88. [CrossRef]

51. Kim, Y.; Tomé, W.A. Risk-adaptive optimization: Selective boosting of high-risk tumor subvolumes. Int. J. Radiat. Oncol. Biol. Phy. 2006, 66, 1528-1542. [CrossRef]

52. Levegrün, S.; Jackson, A.; Zelefsky, M.J.; Venkatraman, E.S.; Skwarchuk, M.W.; Schlegel, W.; Fuks, Z.; Leibel, S.A.; Ling, C.C. Risk group dependence of dose-response for biopsy outcome after three-dimensional conformal radiation therapy of prostate cancer. Radiother. Oncol. 2002, 63, 11-26. [CrossRef]

53. Källman, P.; Agren, A.; Brahme, A. Tumour and normal tissue responses to fractionated non-uniform dose delivery. Int. J. Radiat. Biol. 1992, 62, 249-262. [CrossRef] [PubMed]

54. Uzan, J.; Nahum, A.E.; Syndikus, I. Prostate Dose-painting Radiotherapy and Radiobiological Guided Optimisation Enhances the Therapeutic Ratio. Clin. Oncol. 2016, 28, 165-170. [CrossRef]

55. Betts, J.M.; Mears, C.; Reynolds, H.M.; Tack, G.; Leo, K.; Ebert, M.A.; Haworth, A. Optimised Robust Treatment Plans for Prostate Cancer Focal Brachytherapy. Procedia Comput. Sci. 2015, 51, 914-923. [CrossRef]

56. Betts, J.M.; Mears, C.; Reynolds, H.M.; Ebert, M.A.; Haworth, A. Prostate cancer focal brachytherapy: Improving treatment plan robustness using a convolved dose rate model. Procedia Comput. Sci. 2017, 108, 1522-1531. [CrossRef]

57. Haworth, A.; Mears, C.; Betts, J.M.; Reynolds, H.M.; Tack, G.; Leo, K.; Williams, S.; Ebert, M.A. A radiobiology-based inverse treatment planning method for optimisation of permanent 1-125 prostate implants in focal brachytherapy. Phys. Med. Biol. 2016, 61, 430-444. [CrossRef] [PubMed]

58. Zeng, J.; Bauer, J.J.; Mun, S.K. Modeling and mapping of prostate cancer. Comput. Graph. 2000, 24, 683-694. [CrossRef]

59. Dirscherl, T.; Rickhey, M.; Bogner, L. Feasibility of TCP-based dose painting by numbers applied to a prostate case with 18F-Choline PET imaging. Zeitschrift für Medizinische Physik 2012, 22, 48-57. [CrossRef]

60. Ebert, M.A.; Hoban, P.W. Some characteristics of tumour control probability for heterogeneous tumours. Phys. Med. Biol. 1996, 41, 2125-2133. [CrossRef]

61. Grönlund, E.; Johansson, S.; Nyholm, T.; Thellenberg, C.; Ahnesjö, A. Dose painting of prostate cancer based on Gleason score correlations with apparent diffusion coefficients. Acta Oncol. 2018, 57, 574-581. [CrossRef]

62. Chaddad, A.; Kucharczyk, M.J.; Niazi, T. Multimodal Radiomic Features for the Predicting Gleason Score of Prostate Cancer. Cancers 2018, 10, 249. [CrossRef]

63. Hambrock, T.; Somford, D.M.; Huisman, H.J.; van Oort, I.M.; Witjes, J.A.; Hulsbergen-van de Kaa, C.A.; Scheenen, T.; Barentsz, J.O. Relationship between apparent diffusion coefficients at 3.0-T MR imaging and Gleason grade in peripheral zone prostate cancer. Radiology 2011, 259, 453-461. [CrossRef] [PubMed]

64. Lee, J.; Carver, E.; Feldman, A.; Pantelic, M.V.; Elshaikh, M.; Wen, N. Volumetric and Voxel-Wise Analysis of Dominant Intraprostatic Lesions on Multiparametric MRI. Front. Oncol. 2019, 9, 616. [CrossRef] [PubMed]

65. Sun, Y.; Reynolds, H.; Wraith, D.; Williams, S.; Finnegan, M.E.; Mitchell, C.; Murphy, D.; Ebert, M.A.; Haworth, A. Predicting prostate tumour location from multiparametric MRI using Gaussian kernel support vector machines: A preliminary study. Australas. Phys. Eng. 2017. [CrossRef] [PubMed]

66. Chen, Q.; Hu, S.; Long, P.; Lu, F.; Shi, Y.; Li, Y. A Transfer Learning Approach for Malignant Prostate Lesion Detection on Multiparametric MRI. Technol. Cancer Res. Treat. 2019, 18. [CrossRef]

67. Wang, Z.; Liu, C.; Cheng, D.; Wang, L.; Yang, X.; Cheng, K.-T. Automated Detection of Clinically Significant Prostate Cancer in mp-MRI Images Based on an End-to-End Deep Neural Network. IEEE Trans. Med. Imaging 2018, 37, 1127-1139. [CrossRef]

68. Algohary, A.; Viswanath, S.; Shiradkar, R.; Ghose, S.; Pahwa, S.; Moses, D.; Jambor, I.; Shnier, R.; Böhm, M.; Haynes, A.-M.; et al. Radiomic features on MRI enable risk categorization of prostate cancer patients on active surveillance: Preliminary findings. J. Magn. Reson. Imaging 2018. [CrossRef] 
69. Toivonen, J.; Montoya Perez, I.; Movahedi, P.; Merisaari, H.; Pesola, M.; Taimen, P.; Boström, P.J.; Pohjankukka, J.; Kiviniemi, A.; Pahikkala, T.; et al. Radiomics and machine learning of multisequence multiparametric prostate MRI: Towards improved non-invasive prostate cancer characterization. PLoS ONE 2019, 14, e0217702. [CrossRef]

70. Hectors, S.J.; Cherny, M.; Yadav, K.K.; Beksaç, A.T.; Thulasidass, H.; Lewis, S.; Davicioni, E.; Wang, P.; Tewari, A.K.; Taouli, B. Radiomics Features Measured with Multiparametric Magnetic Resonance Imaging Predict Prostate Cancer Aggressiveness. J. Urol. 2019, 202, 498-505. [CrossRef]

71. Sun, Y.; Reynolds, H.M.; Wraith, D.; Williams, S.; Finnegan, M.E.; Mitchell, C.; Murphy, D.; Haworth, A. Automatic stratification of prostate tumour aggressiveness using multiparametric MRI: A horizontal comparison of texture features. Acta Oncol. 2019, 58,1-9. [CrossRef]

72. Li, J.; Weng, Z.; Xu, H.; Zhang, Z.; Miao, H.; Chen, W.; Liu, Z.; Zhang, X.; Wang, M.; Xu, X.; et al. Support Vector Machines (SVM) classification of prostate cancer Gleason score in central gland using multiparametric magnetic resonance images: A cross-validated study. Eur. J. Radiol. 2018, 98, 61-67. [CrossRef]

73. Varghese, B.; Chen, F.; Hwang, D.; Palmer, S.L.; De Castro Abreu, A.L.; Ukimura, O.; Aron, M.; Aron, M.; Gill, I.; Duddalwar, V.; et al. Objective risk stratification of prostate cancer using machine learning and radiomics applied to multiparametric magnetic resonance images. Scientific Rep. 2019, 9, 1-10. [CrossRef] [PubMed]

74. Rastinehad, A.R.; Baccala, A.A.; Chung, P.H.; Proano, J.M.; Kruecker, J.; Xu, S.; Locklin, J.K.; Turkbey, B.; Shih, J.; Bratslavsky, G.; et al. D'Amico Risk Stratification Correlates with Degree of Suspicion of Prostate Cancer on Multi-Parametric Magnetic Resonance Imaging (MRI). J. Urol 2011, 185, 815-820. [CrossRef] [PubMed]

75. Haworth, A.; Sun, Y.; Ebert, M.; Reynolds, H.; Betts, J.; Wraith, D.; Mitchell, C. Incorporating a Novel Radiomics Framework for Biologically Optimised Prostate RadioTherapy (BiRT). Med. Phys. 2018, 45, E446.

76. Sun, Y.; Reynolds, H.M.; Wraith, D.; Williams, S.; Finnegan, M.E.; Mitchell, C.; Murphy, D.; Haworth, A. Voxel-wise prostate cell density prediction using multiparametric magnetic resonance imaging and machine learning. Acta Oncol. 2018, 57, 1-7. [CrossRef] [PubMed]

77. Reynolds, H.M.; Williams, S.; Jackson, P.; Mitchell, C.; Hofman, M.S.; Hicks, R.J.; Murphy, D.G.; Haworth, A. Voxel-wise correlation of positron emission tomography/computed tomography with multiparametric magnetic resonance imaging and histology of the prostate using a sophisticated registration framework. BJU Int. 2018, 123, 1020-1030. [CrossRef]

78. Her, E.; Sun, Y.; Kennedy, A.; Reynolds, H.M.; Williams, S.; Ebert, M.A.; Haworth, A. Biological optimization of prostate IMRT with patient-specific image-derived cancer biology. J. Med. Imaging Radiat. Oncol. 2017, 61, 103.

79. Her, E.; Sun, Y.; Ebert, M.A.; Reynolds, H.M.; Kennedy, A.; Haworth, A.; Williams, S. O99 Biofocused approach to prostate cancer IMRT planning with voxel-level cancer biology derived from multiparametric MRI. Australas. Phys. Eng. Sci. Med. 2018, 41, 314.

80. Fuks, Z.; Kolesnick, R. Engaging the vascular component of the tumor response. Cancer Cell 2005, 8, 89-91. [CrossRef]

81. Garcia-Barros, M.; Paris, F.; Cordon-Cardo, C.; Lyden, D.; Rafii, S.; Haimovitz-Friedman, A.; Fuks, Z.; Kolesnick, R. Tumor response to radiotherapy regulated by endothelial cell apoptosis. Science 2003, 300, 1155-1159. [CrossRef]

82. Park, H.J.; Griffin, R.J.; Hui, S.; Levitt, S.H.; Song, C.W. Radiation-Induced Vascular Damage in Tumors: Implications of Vascular Damage in Ablative Hypofractionated Radiotherapy (SBRT and SRS). Radiat. Res. 2012, 177, 311-327. [CrossRef]

83. Schneider, B.F.; Eberhard, D.A.; Steiner, L.E. Histopathology of arteriovenous malformations after gamma knife radiosurgery. J. Neurosurg. 1997, 87, 352-357. [CrossRef] [PubMed]

84. Lee, Y.; Auh, S.L.; Wang, Y.; Burnette, B.; Wang, Y.; Meng, Y.; Beckett, M.; Sharma, R.; Chin, R.; Tu, T.; et al. Therapeutic effects of ablative radiation on local tumor require CD8+ T cells: Changing strategies for cancer treatment. Blood 2009, 114, 589-595. [CrossRef] [PubMed]

85. Demaria, S.; Ng, B.; Devitt, M.L.; Babb, J.S.; Kawashima, N.; Liebes, L.; Formenti, S.C. Ionizing radiation inhibition of distant untreated tumors (abscopal effect) is immune mediated. Int. J. Radiat. Oncol. Biol. Phys. 2004, 58, 862-870. [CrossRef] [PubMed] 
86. Her, E.J.; Reynolds, H.M.; Mears, C.; Williams, S.; Moorehouse, C.; Millar, J.L.; Ebert, M.A.; Haworth, A. Radiobiological parameters in a tumour control probability model for prostate cancer LDR brachytherapy. Phys. Med. Biol. 2018, 63, 135011. [CrossRef]

87. Lemaître, G.; Martí, R.; Freixenet, J.; Vilanova, J.C.; Walker, P.M.; Meriaudeau, F. Computer-Aided Detection and diagnosis for prostate cancer based on mono and multi-parametric MRI: A review. Comput. Biol. Med. 2015, 60, 8-31. [CrossRef]

88. de Rooij, M.; Hamoen, E.H.J.; Fütterer, J.J.; Barentsz, J.O.; Rovers, M.M. Accuracy of Multiparametric MRI for Prostate Cancer Detection: A Meta-Analysis. Am. J. Roentgenol. 2014, 202, 343-351. [CrossRef]

89. Sun, Y.; Reynolds, H.M.; Parameswaran, B.; Wraith, D.; Finnegan, M.E.; Williams, S.; Haworth, A. Multiparametric MRI and radiomics in prostate cancer: A review. Australas. Phys. Eng. Sci. Med. 2019, 42, 3-25. [CrossRef]

90. Kim, Y.; Tomé, W.A. Dose-painting IMRT optimization using biological parameters. Acta Oncol. 2010, 49, 1374-1384. [CrossRef]

91. Landberg, T.; Chavaudra, J.; Dobbs, J.; Gerard, J.-P.; Hanks, G.; Horiot, J.-C.; Johansson, K.-A.; Möller, T.; Purdy, J.; Suntharalingam, N.; et al. Report 62. J. Int. Commission Radiat. Units Measurements 1999, os32. [CrossRef]

92. Unkelbach, J.; Alber, M.; Bangert, M.; Bokrantz, R.; Chan, T.C.Y.; Deasy, J.O.; Fredriksson, A.; Gorissen, B.L.; van Herk, M.; Liu, W.; et al. Robust radiotherapy planning. Phys. Med. Biol. 2018, 63, 22TR02. [CrossRef]

93. Bangert, M.; Hennig, P.; Oelfke, U. Analytical probabilistic modeling for radiation therapy treatment planning. Phys. Med. Biol. 2013, 58, 5401-5419. [CrossRef] [PubMed]

94. Baum, C.; Alber, M.; Birkner, M.; Nüsslin, F. Robust treatment planning for intensity modulated radiotherapy of prostate cancer based on coverage probabilities. Radiother. Oncol. 2006, 78, 27-35. [CrossRef] [PubMed]

95. Bohoslavsky, R.; Witte, M.G.; Janssen, T.M.; van Herk, M. Probabilistic objective functions for margin-less IMRT planning. Phys. Med. Biol. 2013, 58, 3563-3580. [CrossRef] [PubMed]

96. Chan, T.C.Y.; Bortfeld, T.; Tsitsiklis, J.N. A robust approach to IMRT optimization. Phys. Med. Biol. 2006, 51, 2567-2583. [CrossRef]

97. Chan, T.C.Y.; Mišić, V.V. Adaptive and robust radiation therapy optimization for lung cancer. Eur. J. Operat. Res. 2013, 231, 745-756. [CrossRef]

98. Lowe, M.; Aitkenhead, A.; Albertini, F.; Lomax, A.J.; MacKay, R.I. A robust optimisation approach accounting for the effect of fractionation on setup uncertainties. Phys. Med. Biol. 2017, 62, 8178-8196. [CrossRef]

99. Unkelbach, J.; Oelfke, U. Inclusion of organ movements in IMRT treatment planning via inverse planning based on probability distributions. Phys. Med. Biol. 2004, 49, 4005-4029. [CrossRef]

100. Witte, M.G.; van der Geer, J.; Schneider, C.; Lebesque, J.V.; Alber, M.; van Herk, M. IMRT optimization including random and systematic geometric errors based on the expectation of TCP and NTCP: Optimization of expected TCP and NTCP. Med. Phys. 2007, 34, 3544-3555. [CrossRef]

101. Brenner, D.J.; Hall, E.J. Fractionation and protraction for radiotherapy of prostate carcinoma. Int. J. Radiat. Oncol. Biol. Phys. 1999, 43, 1095-1101. [CrossRef]

102. Fowler, J.; Chappell, R.; Ritter, M. Is alpha/beta for prostate tumors really low? Int. J. Radiat. Oncol. Biol. Phys. 2001, 50, 1021-1031. [CrossRef]

103. Wang, J.Z.; Guerrero, M.; Li, X.A. How low is the alpha/beta ratio for prostate cancer? Int. J. Radiat. Oncol. Biol. Phys. 2003, 55, 194-203. [CrossRef]

104. Brenner, D.J. Fractionation and late rectal toxicity. Int. J. Radiat. Oncol. Biol. Phys. 2004, 60, $1013-1015$. [CrossRef] [PubMed]

105. Rana, S.; Rogers, K. Radiobiological Impact of Acuros XB Dose Calculation Algorithm on Low-Risk Prostate Cancer Treatment Plans Created by RapidArc Technique. Austral-Asian J. Cancer 2012, 11, 261-269.

106. Abu-Gheida, I.; Reddy, C.A.; Kotecha, R.; Weller, M.A.; Shah, C.; Kupelian, P.A.; Mian, O.; Ciezki, J.P.; Stephans, K.L.; Tendulkar, R.D. Ten-year outcomes of moderately hypofractionated (70 Gy in 28 fractions) intensity modulated radiotherapy for localized prostate cancer. Int. J. Radiat. Oncol. Biol. Phys. 2019. [CrossRef]

107. Catton, C.N.; Lukka, H.; Julian, J.A.; Gu, C.-S.; Martin, J.; Supiot, S.; Chung, P.W.M.; Bauman, G.; Bahary, J.-P.; Ahmed, S.; et al. A randomized trial of a shorter radiation fractionation schedule for the treatment of localized prostate cancer. JCO 2016, 34, 5003. [CrossRef] 
108. Dearnaley, D.; Syndikus, I.; Mossop, H.; Khoo, V.; Birtle, A.; Bloomfield, D.; Graham, J.; Kirkbride, P.; Logue, J.; Malik, Z.; et al. Conventional versus hypofractionated high-dose intensity-modulated radiotherapy for prostate cancer: 5-year outcomes of the randomised, non-inferiority, phase $3 \mathrm{CHHiP}$ trial. Lancet Oncol. 2016, 17, 1047-1060. [CrossRef]

109. Katz, A.J.; Kang, J. Quality of Life and Toxicity after SBRT for Organ-Confined Prostate Cancer, a 7-Year Study. Front. Oncol. 2014, 4, 301. [CrossRef]

110. Loblaw, A.; Cheung, P.; D'Alimonte, L.; Deabreu, A.; Mamedov, A.; Zhang, L.; Tang, C.; Quon, H.; Jain, S.; Pang, G.; et al. Prostate stereotactic ablative body radiotherapy using a standard linear accelerator: Toxicity, biochemical, and pathological outcomes. Radiother. Oncol. 2013, 107, 153-158. [CrossRef]

111. Tiberi, D.; Vavassis, P.; Nguyen, D.; Yassa, M. Hypofractionation for prostate cancer: An update. Expert Rev. Endocrinol. Metab. 2017, 12, 199-205. [CrossRef]

112. Widmark, A.; Gunnlaugsson, A.; Beckman, L.; Thellenberg-Karlsson, C.; Hoyer, M.; Lagerlund, M.; Fransson, P.; Kindblom, J.; Ginman, C.; Johansson, B.; et al. Extreme Hypofractionation versus Conventionally Fractionated Radiotherapy for Intermediate Risk Prostate Cancer: Early Toxicity Results from the Scandinavian Randomized Phase III Trial "HYPO-RT-PC". Int. J. Radiat. Oncol. Biol. Phys. 2016, 96, 938-939. [CrossRef]

113. Widmark, A.; Gunnlaugsson, A.; Beckman, L.; Thellenberg-Karlsson, C.; Hoyer, M.; Lagerlund, M.; Kindblom, J.; Ginman, C.; Johansson, B.; Björnlinger, K.; et al. Ultra-hypofractionated versus conventionally fractionated radiotherapy for prostate cancer: 5-year outcomes of the HYPO-RT-PC randomised, non-inferiority, phase 3 trial. Lancet 2019, 394, 385-395. [CrossRef]

114. Koontz, B.F.; Bossi, A.; Cozzarini, C.; Wiegel, T.; D'Amico, A. A systematic review of hypofractionation for primary management of prostate cancer. Eur. Urol. 2015, 68, 683-691. [CrossRef]

115. Wortel, R.C.; Hoop, E.O.; Heemsbergen, W.D.; Pos, F.J.; Incrocci, L. Moderate Hypofractionation in Intermediate- and High-Risk, Localized Prostate Cancer: Health-Related Quality of Life From the Randomized, Phase 3 HYPRO Trial. Int. J. Radiat. Oncol. Biol. Phys. 2019, 103, 823-833. [CrossRef] [PubMed]

116. Onjukka, E.; Uzan, J.; Baker, C.; Howard, L.; Nahum, A.; Syndikus, I. Twenty Fraction Prostate Radiotherapy with Intra-prostatic Boost: Results of a Pilot Study. Clin. Oncol. 2017, 29, 6-14. [CrossRef] [PubMed]

117. Gatenby, R.A.; Silva, A.S.; Gillies, R.J.; Frieden, B.R. Adaptive Therapy. Cancer Res. 2009, 69, 4894-4903. [CrossRef]

118. Berwouts, D.; Olteanu, L.A.M.; Duprez, F.; Vercauteren, T.; De Gersem, W.; De Neve, W.; Van de Wiele, C.; Madani, I. Three-phase adaptive dose-painting-by-numbers for head-and-neck cancer: Initial results of the phase I clinical trial. Radiother. Oncol. 2013, 107, 310-316. [CrossRef]

119. Differding, S.; Sterpin, E.; Janssens, G.; Hanin, F.-X.; Lee, J.A.; Grégoire, V. Methodology for adaptive and robust FDG-PET escalated dose painting by numbers in head and neck tumors. Acta Oncol. 2016, 55, 217-225. [CrossRef]

120. Duprez, F.; De Neve, W.; De Gersem, W.; Coghe, M.; Madani, I. Adaptive Dose Painting by Numbers for Head-and-Neck Cancer. Int. J. Radiat. Oncol. Biol. Phys. 2011, 80, 1045-1055. [CrossRef]

121. Servagi-Vernat, S.; Differding, S.; Sterpin, E.; Hanin, F.-X.; Labar, D.; Bol, A.; Lee, J.A.; Grégoire, V. Hypoxia-guided adaptive radiation dose escalation in head and neck carcinoma: A planning study. Acta Oncol. 2015, 54, 1008-1016. [CrossRef]

(C) 2020 by the authors. Licensee MDPI, Basel, Switzerland. This article is an open access article distributed under the terms and conditions of the Creative Commons Attribution (CC BY) license (http://creativecommons.org/licenses/by/4.0/). 